\title{
THE MANAGEMENT OF "UNKNOWN" OR "UNIDENTIFIED" DECEASED ALLEGED TO BE INVOLVED IN ROAD TRAFFIC ACCIDENTS; ARE WE HELPING ADEQUATELY TO PROVIDE JUSTICE TO THEM?
}

\author{
Edirisinghe P.A.S. \\ Senior Lecturer, Department of Forensic Medicine, Faculty of Medicine, \\ University of Kelaniya
}

\section{INTRODUCTION}

In modern societies identification of human remains and ascertaining the cause of death are necessary for legal and social reasons ${ }^{1}$. In a case of an alleged traffic accident the need is highlighted more as the damage to persons and property can lead to compensation issues and implementation of preventive measures. Proper management of "unknown" or "unidentified" body remains due to trauma is a challenge to any medico-legal system since it involves several stake holders namely, the Police, Judiciary, Health Servicers, Local Authorities, Funeral Services as well as the loved ones of a 'missing person'. The management includes storage of the body in a refrigerator, initiation of investigations, identification of the individual, getting an order to conduct the autopsy, postmortem examination, reporting and burial of the deceased. Issuing of a magistrate order stating the remains to be stored in morgue freezers until the appearance of relatives has created a huge problem where the freezers are almost always overcrowded and not functioning at their optimum conditions. This in turn led to cascade of events where the investigation becomes a fruitless exercise. The two cases given here highlight the issues.

\section{Case Report-1}

A male involved in a "hit and run" by a van was subjected to a post-mortem examination 6 months later by a magistrate order. Although body was brought to the mortuary in a relatively fresh state for refrigeration by the time of the autopsy, it was highly putrefied [Figure:1]. The soft tissues were liquefied and large collections of dead maggots were found. There were no bone injuries. Skeletal examination revealed the estimated age between $30-40$ years. The cause of death was given as unascertainable.

\section{Case Report-2}

An autopsy of an "unknown" pedestrian involved in a road traffic accident was conducted 4 months later after refrigeration. According to the police information the deceased was a destitute hit by a speeding vehicle while crossing the road at yellow lines. The body was in an advanced state of putrefaction at the time of the autopsy. Skeletal examination revealed fracture of the cervical spine at $\mathrm{C} 4$ level and multiple rib fractures. [Figure:2\& 3] Cause of death was given as multiple injuries to the neck and chest based on skeletal injuries. Collection of data for specific identification from soft tissue was impossible and only option was obtaining a DNA sample.

\section{DISCUSSION}

Post-mortem examination of a deceased where cause of death is related to trauma, if not examined early may lead to various problems especially in injury interpretations. Postmortem changes are well known for their possible misinterpretation as traumatic lesions and vice versa and therefore early examination of the body is the recommended practice ${ }^{2,3,4}$.

The first step of the management of the "unknown/ unidentified" body is finding a hospital with "refrigerator" facility to store the body. In routine practice the Police publish information of the deceased in media and give some time for the relatives/next of kin to come forward for identification. The time duration given to identify the deceased by relatives varies according to the stake holders involved in the process. However, when the Magistrate issues an order for post-mortem examination it is not only to find the cause of death but also to establish the identification of the deceased. Order for an autopsy usually issued along with a burial order to use the Government funds to burry if no relative comes forward to claim the remains. 
The two case reports highlight few common issues related to the management of the 'unknown' involved in road traffic accidents. Although the bodies were "refrigerated" they undergo putrefaction leading to many other problems to the system simply because the refrigerators were not functioning in their optimal conditions due to overcrowding [Figure: 4,5,6]. One of the most important issues is difficulty in interpreting injuries thus leading inability to find a cause of death which in turn will lead to problems in serving justice to the dead.

The issues faced by pathologists and hospital administrators due to delay in obtaining a Magistrate Order are collection of "unknown" bodies in the freezers leading to overloading of refrigerators, mechanical failure of the refrigerators, decomposition of the bodies, unbearable ordure in the mortuary and hospital, maggot infestation, environmental and health issues, and logistic problems to the systems. Problems related to hospital mortuary freezer overcrowding is a universal problem ${ }^{5,6,7}$. Although many may interpret the problem as a consequence of poor funding and capacity, the management failure also play a significant role ${ }^{6}$.

Sri Lanka is a tropical country that enhances putrefaction of the bodies quickly due to high temperatures, especially those where exposed to the environment even the body is refrigerated later. Refrigerator/freezer facility is any way poor in majority of hospitals in Sri Lanka. Inadequate funding for their maintenance further worsens the situation. Overcrowding of freezers due to management inadequacy of the burials/cremations of body lead to cascade of events where the freezers come to the level of mechanical failure, enhancing the putrefaction more.

Therefore, the need of standard operational procedures for the management of 'unknown' involved in road traffic accident is felt more and more if we are to give justice to the deceased and the society. Currently Sri Lankan medicolegal investigators lack operational procedures in the investigation of "unknown/unidentified". Hence, practiced operational procedures vary from one hospital to the other leading to different standards even among specialist's investigations.

\section{CONCLUSION}

Thus, my suggestion is that the Magistrates to issue orders for a post-mortems of the 'unknown' involved in traffic accidents to be conducted with 2-3 days to ensure a quality work from the pathologist, considering the cause of death. Further, I suggest the data related to identification of the deceased to be done methodically according to "Disaster victim identification form" developed by Interpol which in turn can be compared with data from the "missing individuals" properly. Therefore, time has come to develop standard operational procedures related to management of the unknown involved in trauma if we are to help serving justice to them.

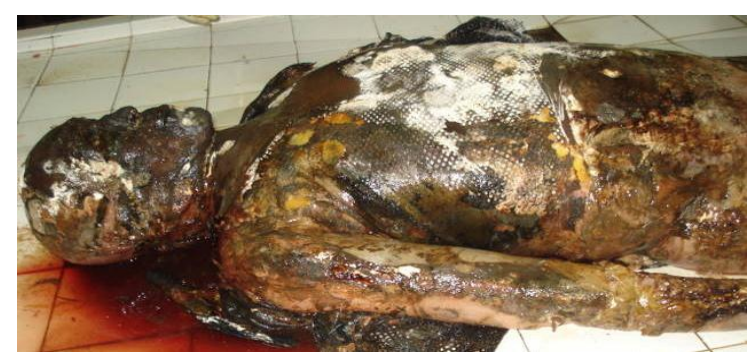

Figure: 1-Putrefied body

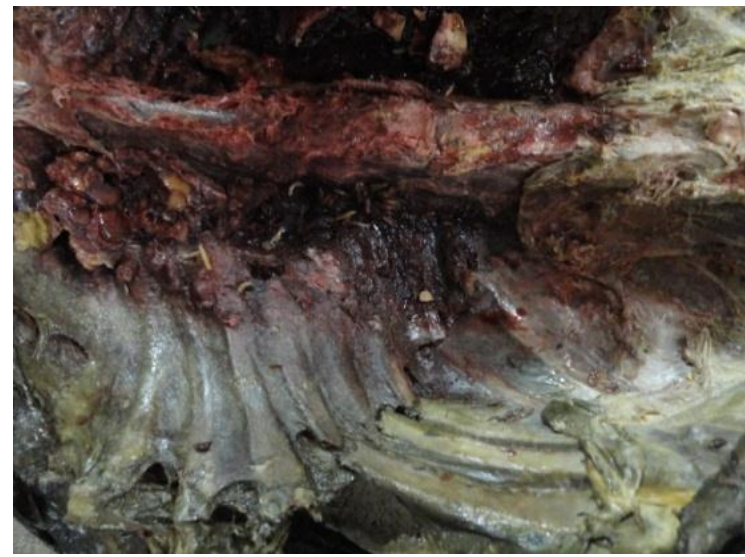

Figure: 2 - Traumatic injuries- Rib fractures in putrefied body 


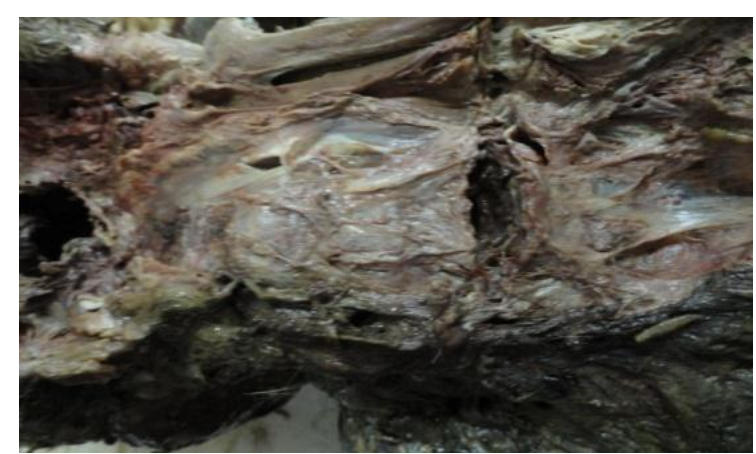

Figure:3-Traumatic injuries-cervical fractures in putrefied body

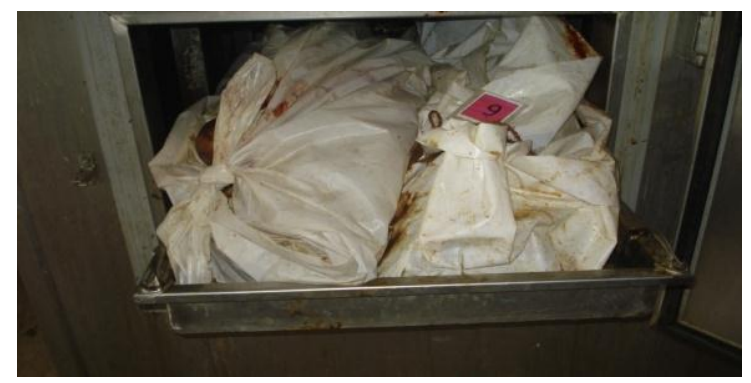

Figure: 5 - Overcrowding - two bodies in one tray

\section{ACKNOWLEDGEMENT}

Dr. W.R.A.S. Rajapaksha for providing details of the Case 1 .

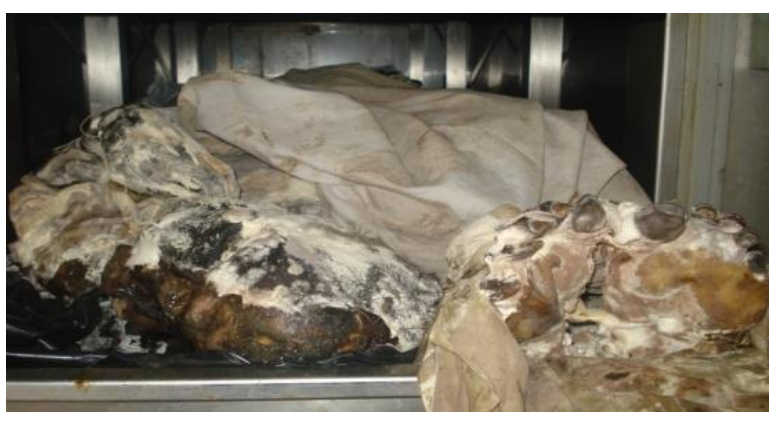

Figure: 4- overcrowding - two bodies in one tray

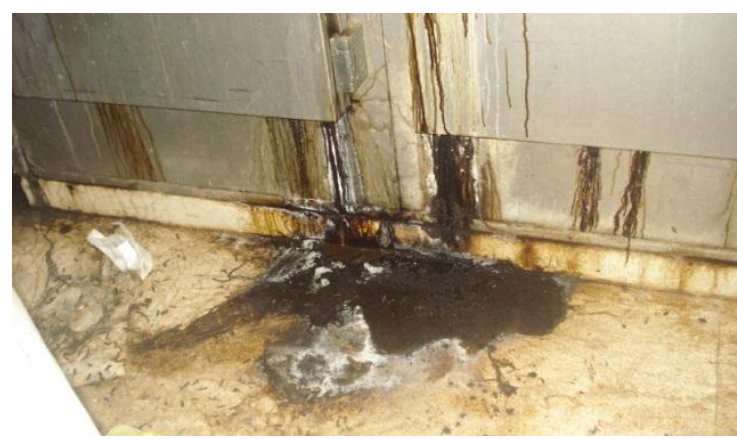

Figure: 6- purified fluids damaging refrigerators

\section{REFERENCE}

1. Buchner A. The identification of human remains. Int Dent J. 1985;35(4):307-11.

2. Sauvageau A, Racette S. Postmortem changes mistaken for traumatic lesions: a highly prevalent reason for coroner's autopsy request. Am J Forensic Med Pathol. 2008;29(2):145-7.

3. James R, Gilbert J, Byard RW Posttraumatic diaphragmatic hernia and death--etiologic factor or putrefactive artifact? Am J Forensic Med Pathol. 1999;20(1):66-9.

4. $\quad \mathrm{P}$ Vanezis Interpreting bruises at necropsy. J Clin Pathol .2001;54:348-355

5. Abbasi K. Death underfunded. BMJ.2001;322:186.

6. Frampton M. Mortuary facilities. Funding is needed, not scapegoats. BMJ. 2001; 28;322 (7293): 1066.

7. Hayman J. Mortuary facilities. These facilities are inadequate in Australia too. BMJ. 2001 28;322 (7293): 1066. 